\title{
Application of Performance based Seismic Design Method to Column Discontinued RC Frames
}

\author{
Dubal R.A \\ Resarch Scholar \\ Applied Mechanics Dept \\ SVNIT, Surat
}

\author{
Vasanwala S.A \\ Professor \\ Applied Mechanics Dept \\ SVNIT, Surat
}

\author{
Modhera C.D \\ Professor \\ Applied Mechanics Dept \\ SVNIT, Surat
}

\begin{abstract}
A performance-based seismic design (PBSD) method is aimed at controlling the structural damage based on precise estimations of proper response parameters. PBSD method evaluates the performance of a building frame for any seismic hazard, the building may experience. Use of this method for vertical irregular building is verified with comparison of conventional method. Vertical irregular frame is subjected to failures due to stiffness and strength reduction. This paper deals with application of performance based seismic design method for vertical irregular RC building frames(10 storied).Performance evaluation of conventional frames designed by conventional code method is compared with performance based seismic designed frames. The evaluation is carried out by Nonlinear Time History Analysis and Nonlinear Static analysis. The vertical irregular frames considered for study are with column discontinuity.
\end{abstract}

\section{Keywords}

Performance Based Seismic Design Method, Vertical Irregular frames, Performance Evaluation, Nonlinear Time History Analysis.

\section{INTRODUCTION}

It is very clear that major contribution to structural damage is discontinuities or irregularities in the load transfer path. This path is important to transfer of seismic force, which develops due to accelerations of individual elements to ground. Development of distress is result of vertical irregularity may lead to complete collapse of structure[1]. The examples of load path irregularities are discontinuous columns, shear walls, bracing etc. To study the effect of discontinuities we have considered 10 storey building frame with column discontinued in each storey which were modified into 10 different model cases. All the selected models were designed as per I.S 456;2000 considering lateral forces in accordance to I.S 1893;2002 and redesigned using Performance based Seismic design method [7]. The method incorporates nonlinear behavior of concrete and accounts for actual lateral force distribution which enhances performance of building in given Seismic hazard. The study focuses on application of Performance based Seismic design method to 10 storied frames with floating columns. This may lead to guidelines for next generation Performance based codes [3].

Table 1: Column discontinued cases

\begin{tabular}{|l|l|}
\hline Case/Model & Type \\
\hline Case 1 & Column discontinued in first floor \\
\hline Case 2 & Column discontinued in second floor \\
\hline
\end{tabular}

\begin{tabular}{|l|l|}
\hline Case 3 & Column discontinued in third floor \\
\hline Case 4 & Column discontinued in fourth floor \\
\hline
\end{tabular}

\subsection{Building model details}

The basic plan and elevation for all 10 models is kept same. Frames are considered of $12 \mathrm{~m} \times 09 \mathrm{~m}$ area. Height of building is $30 \mathrm{~m}$. Following table gives generalized details of frame considered for dimensions of the frame

Table 2: Design Parameters

\begin{tabular}{|l|l|}
\hline Type of frame & Moment Resistant frame \\
\hline Size of column & $500 \times 500 \mathrm{~mm}$ \\
\hline Size of beam & $300 \times 600 \mathrm{~mm}$ \\
\hline Thickness of Slab & $125 \mathrm{~mm}$ \\
\hline Bay & $4 \mathrm{mx} 3 \mathrm{~m}$ \\
\hline Reinforcement & Fe500 \\
\hline Concrete Grade & M30 \\
\hline Load Type(D.L) & Self Weight \\
\hline Load Type(L.L) & $2 \mathrm{KN} / \mathrm{m}^{2}$ \\
\hline Floor finish & $1 \mathrm{KN} / \mathrm{m}^{2}$ \\
\hline Earthquake Loads & $\mathrm{I} . \mathrm{S} 1893-2002$ \\
\hline $\begin{array}{l}\text { Response } \\
\text { Factor }\end{array}$ & 5 \\
\hline Importance Factor & 1 \\
\hline Damping & $5 \%$ \\
\hline
\end{tabular}

\section{ETABS OVERVIEW}

Innovative and revolutionary software by Computers and Structures, ETABS (Extended Three Dimensional Analysis of Building Systems) is regarded as ultimate software package for structural analysis and design of buildings. A sample frame is shown in figure below with floating column at first floor.All model frames are designed as per I.S method and redesigned as per Performance Based Seismic Design method.Following parameters are considered for design. The procedure for Performance based Seismic Design is considered from ASCE 7(2005).The steps describes the PBSD procedure implemented for the frames [7] 
1) Selection of Target Yield Mechanism

2) Determination of Fundamental Time period

3) Calculate Design Base Shear

4) Design Lateral Forces

5) Design of Designated Yielding Members(DYM)

6) Design of Non Designated Yielding Members(Non DYM)

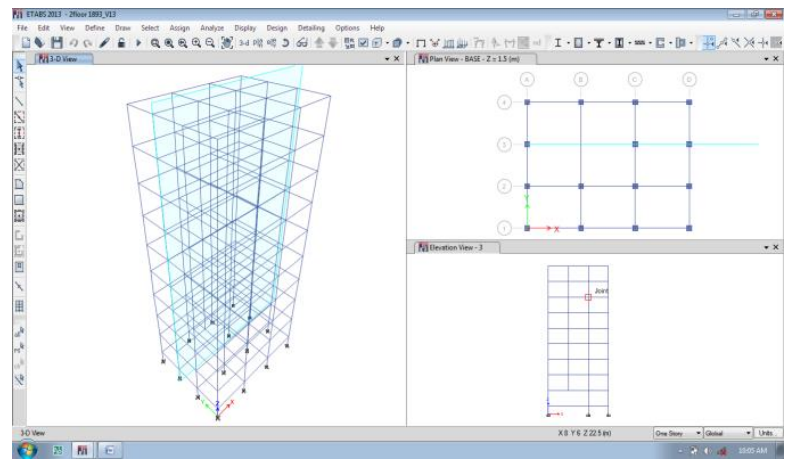

Fig.1. Plan and Elevation of 10 storied irregular frames considered for study

Table 3: Performance based seismic design parameters considered for study

\begin{tabular}{|l|l|}
\hline Seismic zone factor Z & 0.24 \\
\hline Soil Profile Type & Type 2 Medium \\
\hline Importance factor, I & 1 \\
\hline Sa Inelastic & $0.1875 \mathrm{~g}$ \\
\hline $\mathrm{T}$ & $0.8 \mathrm{~s}$ \\
\hline Yield drift ratio $\theta \mathrm{y}$ & $0.5 \%$ \\
\hline Target drift ratio $\theta \mathrm{u}$ & $2 \%$ \\
\hline Inelastic drift ratio $(\theta \mathrm{u}-\theta \mathrm{y})$ & $1.5 \%$ \\
\hline Ductility factor & 4 \\
\hline Energy Modification Factor & 0.43 \\
\hline
\end{tabular}

The frames are designed considering inelastic spectra prescribed by ASCE 7, 2005 and using shear distribution factor and energy modification factor[6].This also includes designing the frame with modified base shear and consideration of stiffness degradation of concrete. Performance evaluation is done using nonlinear static analysis, Response Spectrum and Nonlinear Time History analysis.

\subsection{Performance Evaluation using Non- Linear Response Spectrum Analysis}

In order to get still clear picture of the performance enhancement Non linear Dynamic Analysis is proposed for verification of result [2]. Response Spectrum method estimates the forces in the members of a building corresponding to each natural periods and mode shapes. It requires free vibration analysis to determine natural periods and mode shapes. Peak spectral acceleration of building corresponding to each natural mode is computed using same design spectrum. Peak responses of individual modes are then combined using a suitable modal combination rule to estimate the total peak response of the building. Number of modes to be considered must be such that sum total of modal masses is at-least $90 \%$ of total seismic mass of the building. Following are the results for Response Spectrum Analysis for Story Drift, Diaphragm displacement and Base shear
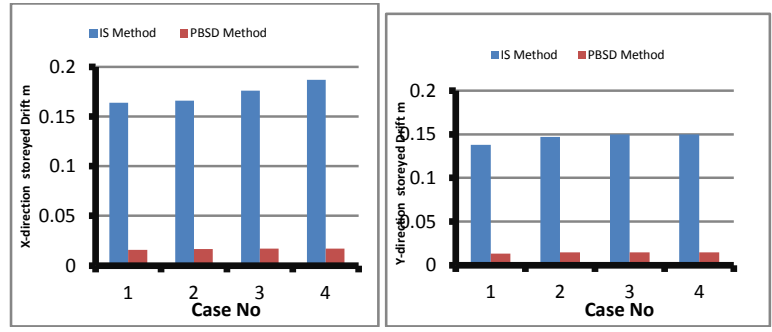

Fig.2. Comparison of Storey Drift in X,Y direction I.S 1893-2002 (force based method) method and PBSD

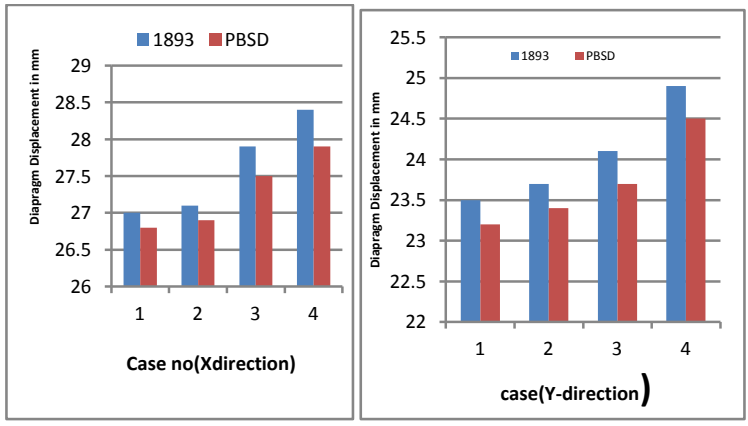

Fig 3 Comparison of Diaphragm Displacement in $\mathrm{X}$ and $\mathrm{Y}$ direction I.S 1893-2002(force based method) method and PBSD
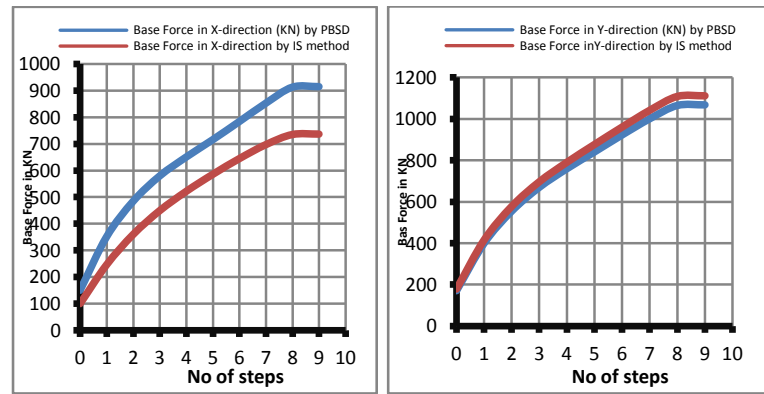

Fig4 Comparison of Base shear in $\mathrm{X}$ and $\mathrm{Y}$ direction I.S 1893-2002(force based method) method and PBSD

\subsection{Comments on results from Response Spectrum Analysis}

In case of Response Spectrum Analysis, Base force for PBSD method in all 5 models is more than IS method .The major difference is seen in first floor model having a difference of $100 \mathrm{kN}$ in Xdirection and $150 \mathrm{kN}$ in Y direction. Inversely the displacement is reduced in PBSD models to a range of $0.025 \mathrm{~m}$ in both directions. Displacement in both directions of PBSD models is $5 \mathrm{~mm}$ less than IS models, which interprets the enhanced performance of the building frame. Storey Drift 
which is major concern is directly reduced to $0.02 \mathrm{~m}$ in all 5 models for PBSD in both directions.Diaphragm displacement in all models is considerably low in PBSD method compared to IS models in both directions. Roof drift reduction in all models is also considerable i.e $10 \mathrm{~mm}$ in all models. As static over strength ratio is governed by member sizes it is less in PBSD method than IS method .For the columns which are discontinued on the floors above sixth floor level, there is no proper significant difference achieved in design done by I.S 1893-2002 method and Performance based Seismic Design method. Hence models having column discontinuity up till fifth floor level are considered for detail study.

\subsection{Performance Evaluation using Non- Linear Time History analysis}

Non-Linear Time History analysis for Bhuj Time history is shown to compare with Response Spectrum Analysis. The results are shown in following figures. The story drift and Diaphragm displacement are given[8].

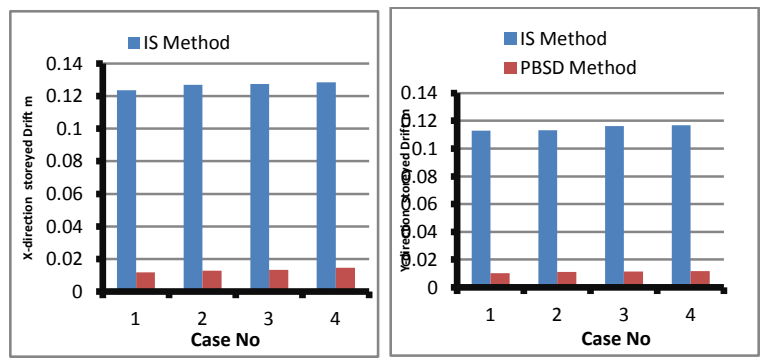

Fig5 Comparison of Story Drift in $\mathrm{X}$ and $\mathrm{Y}$ direction I.S 1893-2002(force based method) method and PBSD

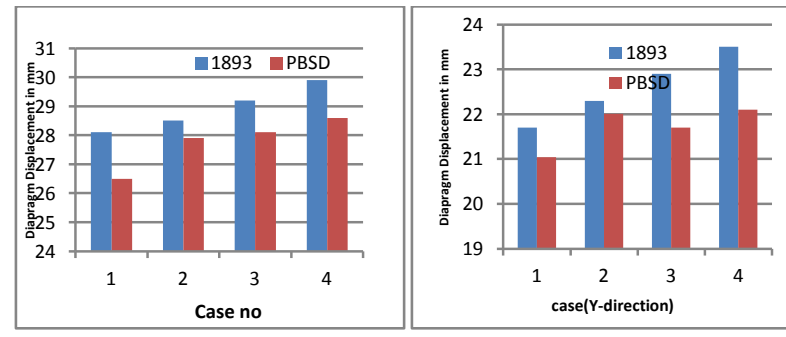

Fig6 Comparison of Diaphragm Displacement in $\mathrm{X}$ and $\mathrm{Y}$ direction I.S 1893-2002(force based method) method and PBSD

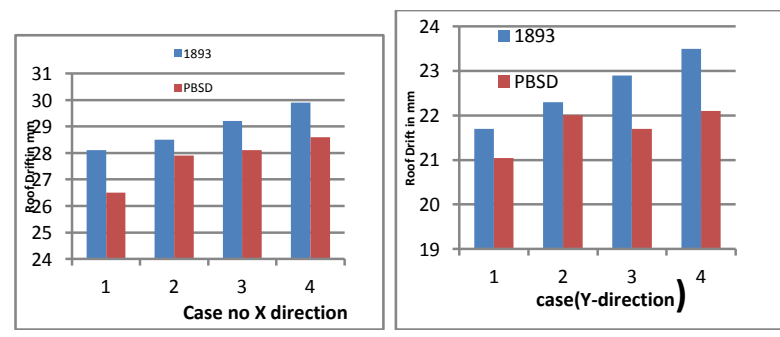

Fig7 Comparison of Roof Drift in $\mathrm{X}$ and $\mathrm{Y}$ direction I.S 1893-2002(force based method) method and PBSD

\subsection{Comments on results from Non-Linear Time History Analysis}

In case of Time History Analysis also Base force for PBSD method in all 5 models is more than IS method .This depicts actual force and its effects on performance after the design[1].The major difference is seen in first floor model having a difference of $109 \mathrm{kN}$ in $\mathrm{X}$ direction and $155 \mathrm{kN}$ in $\mathrm{Y}$ direction. Inversely the displacement is reduced in PBSD models to a range of $0.05 \mathrm{~m}$ in both directions. Displacement in both directions of PBSD models is $5 \mathrm{~mm}$ less than IS models, which interprets the enhanced performance of the building frame. The performance level of the frame is represented with respect to Storey Drift. Storey Drift which is major concern is directly reduced to $0.02 \mathrm{~m}$ in all 5 models for PBSD and $0.12 \mathrm{~m}$ in I.S method in both $\mathrm{X}$ and $\mathrm{Y}$ directions. Diaphragm displacement in all models is considerably low in PBSD method compared to IS models in both directions. Diaphragm displacement is reduced by $2 \mathrm{~mm}$ for all models in PBSD models than I.S models in both directions. Roof drift reduction in all models is also considerable i.e $10 \mathrm{~mm}$ in all models in both directions.

\subsection{Comparison of Response Spectrum and Non-Linear Time history Analysis}

Comparative analysis is done in order to whether the values of both the methods are having any co relevance or not .It is seen that through both the analysis we get same trend which is shown in following figures. Overall values in both the methods have difference of about $2 \mathrm{~mm}$ respectively Diaphragm displacement in I.S models have values from $21 \mathrm{~mm}$ to $22 \mathrm{~mm}$ for Time History Analysis and $23 \mathrm{~mm}$ to $25 \mathrm{~mm}$ for Response Spectrum Analysis in Y direction Roof values from $21 \mathrm{~mm}$ to $22 \mathrm{~mm}$ for Time History Analysis and $23 \mathrm{~mm}$ to $25 \mathrm{~mm}$ for Response Spectrum Analysis in X and Y direction are seen. Inversely the displacement is reduced in PBSD models to a range of $0.025 \mathrm{~m}$ in both directions. Displacement in both directions of PBSD models is $5 \mathrm{~mm}$ less than IS models, which interprets the enhanced performance of the building frame. Storey Drift which is major concern is directly reduced to $0.02 \mathrm{~m}$ in all 5 models for PBSD in both directions. This gives empowerment to use PBSD method for $\mathrm{RC}$ frames with stiffness irregularity[9]. The reduced stiffness makes the other components of frame subjected to additional forces which are not included in force based seismic design practiced normally up till now. This weakness is eliminated in PBSD method [5]

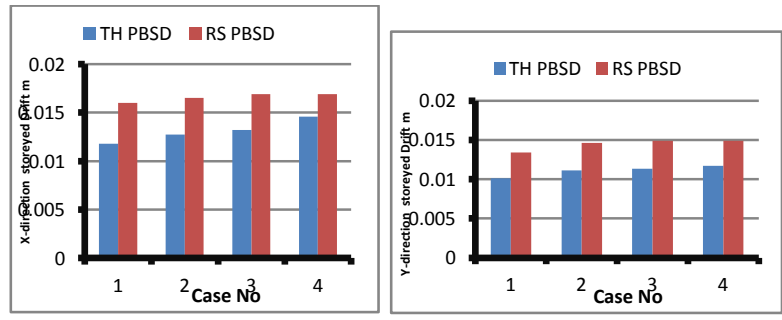

Fig8 Comparison of Storey drift in $\mathrm{X}$ and $\mathrm{Y}$ direction in Response Spectrum and NLTH analysis.

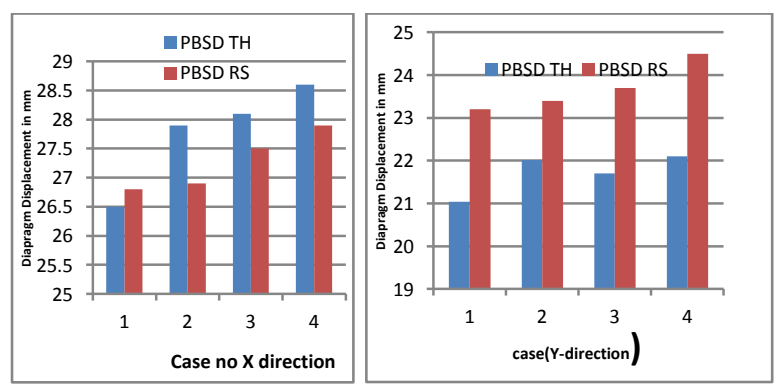

Fig 9 Comparison of Diaphragm displacement in $\mathrm{X}$ and $\mathrm{Y}$ direction in Response Spectrum and NLTH analysis 

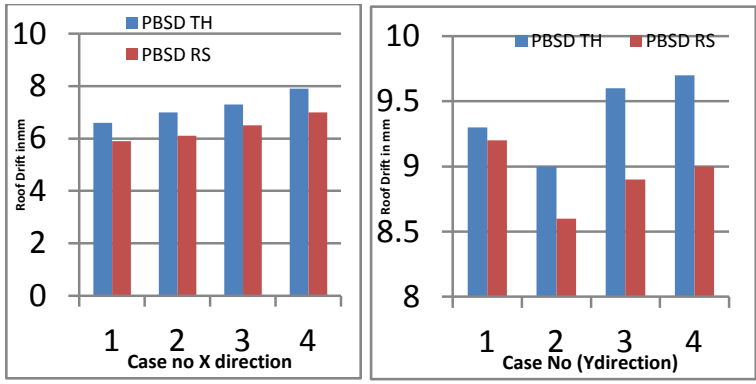

Fig 10 Comparison of Roof drift in $\mathrm{X}$ and $\mathrm{Y}$ direction Response Spectrum and NLTH analysis

The graphs represented in above mentioned section are shown to clearly indicate the difference in the outcomes for PBSD models and I.S models. Enhancing performance for seismic loads is prime concern for structural designers which faces the challenges of ever-changing earthquake scenario. One more parameter is considered for member sizes as the constraints must be considered thoroughly. As static over strength ratio is governed by member sizes it is less in PBSD method than IS method[4].As member size ratio is less in PBSD than member sizes in I.S method the over strength ratio is plotted in graph below.

Assessment of frames also includes acceleration responses, displacement responses and hinge results which also address the performance of both methods. Since the major concerns are story drift, base shear and roof drift the plots are shown with this context [10].

Table 3: Static Over strength Ratio

\begin{tabular}{|l|l|l|}
\hline Case no. & $\begin{array}{l}\text { Static Over Strength } \\
\text { as per I.S 1893;2002 }\end{array}$ & $\begin{array}{l}\text { Static } \\
\text { Strength as per } \\
\text { PBSD }\end{array}$ \\
\hline 05 & 0.512 & 0.28 \\
\hline 04 & 0.9 & 0.28 \\
\hline 03 & 0.32 & 0.0095 \\
\hline 02 & 0.932 & 0.36 \\
\hline 01 & 0.5 & 0.147 \\
\hline
\end{tabular}

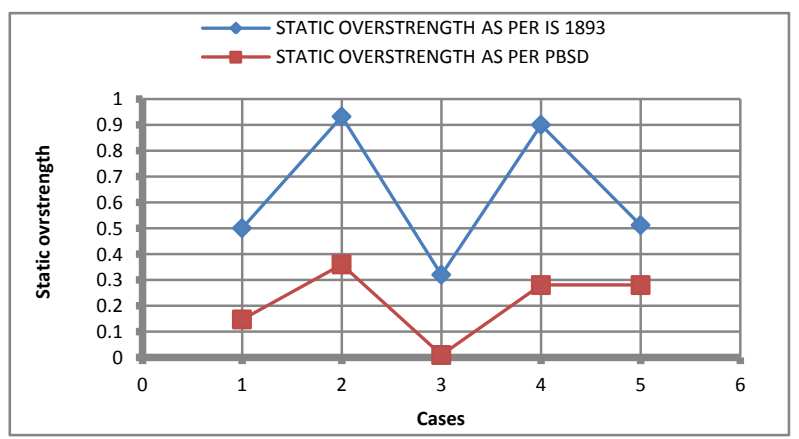

Fig 10 Comparison of static over strength in $\mathrm{X}$ and $\mathrm{Y}$ direction I.S 1893-2002 (force based method) and PBSD method for model with floating columns

\section{CONCLUSION}

Performance Based Seismic Design method implements proper distribution of lateral forces which is dependent on nonlinear behavior and stiffness degradation of material which is not addressed by any conventional method practiced up till now. Performance Based Seismic Design when used to column discontinued frames or floating column frames give better performances as that of frames designed as pr I.S method.

\section{REFERENCES}

[1] Borzi B, Elnashai AS.1998.Assessment of inelastic response of buildings using force- and displacementbased approaches Structures Design Tall Bldgs 2000;9(4):251-77.spectrum”,Journal of Structural Engineering ,ASCE,124( 1998)pg 913-921. .

[2] Chandrasekaran. S. Roy .A(2006).Seismic Evaluation of Multi-Storey RC Frame Using Modal Pushover Analysis",Nonlinear Dynamics 43: pp329-342

[3] Chandler A., Lam Nelson T. K.,2001 Performance-based design in earthquake engineering: a multidisciplinary Review", Engineering Structures 23, pp1525-1543

[4] Chopra .A.K , Dynamics of Structures, Prentice Hall Pvt Ltd 2006

[5] Chopra .A.K , Goel.R.K, 2001. A modal Pushover Analysis Procedure to Estimate Seismic demands for buildings:Theory and Preliminary Evaluation", PEER Report 2001/03 Pacific Earthquake Engineering Research Center College of Engineering,University of California Berkeley

[6] Fajfar P,EERI.M.(2000) "A nonlinear Analysis method for Performance Based Seismic Design", Earthquake Spectra,Vol.16,No 3, pp 573-592

[7] Goel, S. C., Stojadinovic.B., and Leelataviwat S., "Energy-based Seismic Design of Structures using Yield Mechanism and Target Drift", Journal of Structural Engineering.

[8] Kappos AJ, Penelis G G.(1997) Earthquake-resistant Concrete Structures. London: E \& FN SPON", (Chapman \& Hall)

[9] Kowalsky, M.J ,Priestley MJN., “ Displacement-based seismic assessment of reinforced concrete buildings", Journal of Earthquake Engineering 1997;1:15.pp7-92

[10] Priestley M. J. N., Grant D.N.,Blandon.C.A, “Displacement-Based Seismic Design”,NZSEE , (2005) paper no 33 